\title{
Characterizing contributions of glacier melt and groundwater during the dry season in a poorly gauged catchment of the Cordillera Blanca (Peru)
}

\author{
M. Baraer ${ }^{1}$, J. M. McKenzie ${ }^{1}$, B. G. Mark ${ }^{2,3}$, J. Bury ${ }^{4}$, and S. Knox ${ }^{1}$ \\ ${ }^{1}$ Earth and Planetary Sciences, McGill University, 3450 University Street, Montreal, Quebec H3A 2A7, Canada \\ ${ }^{2}$ Department of Geography, The Ohio State University, 1036 Derby Hall, 154 N Oval Mall, Columbus, Ohio 43210, USA \\ ${ }_{3}^{3}$ Byrd Polar Research Center, the Ohio State University, 108 Scott Hall, 1090 Carmack Road, Ohio 43210, USA \\ ${ }^{4}$ Department of Environmental Studies, University of California, Santa Cruz; 1156 High Street, Santa Cruz, \\ California, 95064, USA
}

Received: 12 May 2009 - Revised: 7 August 2009 - Accepted: 9 August 2009 - Published: 13 October 2009

\begin{abstract}
The retreat of glaciers in the tropics will have a significant impact on water resources. In order to overcome limitations with discontinuous to nonexistent hydrologic measurements in remote mountain watersheds, a hydrochemical and isotopic mass balance model is used to identify and characterize dry season water origins at the glacier fed Querococha basin located in southern Cordillera Blanca, Peru. Dry season water samples, collected intermittently between 1998 and 2007, were analyzed for major ions and the stable isotopes of water $\left(\delta^{18} \mathrm{O}\right.$ and $\left.\delta^{2} \mathrm{H}\right)$. The hydrochemical and isotopic data are analysed using conservative characteristics of selected tracers and relative contributions are calculated based on pre-identified contributing sources at mixing points sampled across the basin. The results show that during the dry-season, groundwater is the largest contributor to basin outflow and that the flux of groundwater is temporally variable. The groundwater contribution significantly correlates (P-value $=0.004$ to 0.044$)$ to the antecedent precipitation regime at 3 and $18-36$ months. Assuming this indicates a maximum of 4 years of precipitation accumulation in groundwater reserves, the Querococha watershed outflows are potentially vulnerable to multi-year droughts and climate related changes in the precipitation regime. The results show that the use of hydrochemical and isotopic data can contribute to hydrologic studies in remote, data poor regions, and that groundwater contribution to tropical proglacial hydrologic systems is a critical component of dry season discharge.
\end{abstract}

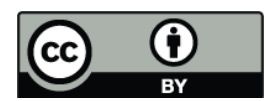

Correspondence to: M. Baraer (michel.baraer@mail.mcgill.ca)

\section{Introduction}

In the tropics, mountain glaciers and seasonal snow pack are an important part of the hydrological cycle as they form the headwaters for hydrologic systems that provide water to some of the most populated areas on earth (Nogues-Bravo et al., 2007). While providing critical hydrologic functionality, glaciers are threatened by ubiquitous recession (Barry, 2006; Kaser et al., 2006; Vuille et al., 2008) that will cause significant hydrologic changes, including a reduction in dryseason water discharge (Barnett et al., 2005), an increase in peak discharges (Mark and Seltzer, 2003), and a general decrease in water resources in Asia, Europe, and the Americas (IPCC, 2007). Despite the threat posed by this ongoing decline, detailed studies of the future impact of global warming on water resources in potentially affected regions are long overdue (Barnett et al., 2005).

Modeling tropical pro-glacial hydrology is important for predicting the future impact of glacial retreat on water resources, but is difficult because of the relatively poor, location specific, understanding of hydrological processes in these remote areas. In addition to glacial melt input, tropical pro-glacial hydrology must include surface and subsurface drainage systems. Although there is extensive research on understanding glacier dynamics in the tropics and modeling gross runoff, there has been very little research focused on the role of groundwater in these systems (Favier et al., 2008; Wagnon et al., 1998). The consequence is that existing proglacial hydrological models frequently oversimplify the input of groundwater to the hydrologic budget (Hood et al., 2006).

Published by Copernicus Publications on behalf of the European Geosciences Union. 
One approach to estimate the contribution of groundwater to stream discharge is to use a hydrochemistry mass balance approach wherein multiple tracers are used to quantify multicomponent mixing (hydrochemistry refers here to dissolved chemical species in water and the stable isotopes, $\delta^{18} \mathrm{O}$ and $\left.\delta^{2} \mathrm{H}\right)$. This potentially useful approach has not yet been thoroughly applied to pro-glacial systems (Brown et al., 2006), although the chemical weathering of rock, sediment, and soil that deeply influence the ionic and isotopic composition of surface and groundwater applies to those environments. The physical weathering processes that occur at the base of a glacier produce fine fresh particles that are particularly reactive to chemical weathering that should be defined by a specific hydrochemical signature for glacial melt water (Anderson, 2005).

In this study we use a hydrochemical basin characterisation method (HBCM) that quantifies the dry season relative contribution of glacial melt water and groundwater components to streams across tributaries of the Querococha watershed, a glacierized $64 \mathrm{~km}^{2}$ large catchment situated in the southern Cordillera Blanca Peru (Fig. 1). The Rio Santa, which drains the glacierized Cordillera Blanca westward to the Pacific, provides an important water source for hydroelectric power generation and irrigation.

\section{Study area}

The Callejon de Huaylas, Peru, is a $4900 \mathrm{~km}^{2}$ watershed that captures runoff from the western side of the Cordillera Blanca and the eastern side of the Cordillera Negra (Fig. 1a). The Rio Santa originates at Laguna Conococha, a shallow lake 4000 meters above sea level (ma.s.1.) and drains the Callejon de Huaylas down to the Cañon del Pato hydropower plant at $1500 \mathrm{~m}$ a.s.l. The Cordillera Blanca has the largest glacierized surface area in the tropics, with a total glacial area of $631 \mathrm{~km}^{2}$ (Suarez et al., 2008), whereas the Cordillera Negra has no glaciers. Between 1970 and 1997 the glacial surface area of the Cordillera Blanca has decreased by approximately 15\% (Pouyaud et al., 2005), and almost all of these glaciers are predicted to potentially disappear by 2200 in many future climate scenarios (Pouyaud, 2004).

Rio Santa historical discharge records from 1991 to 2000 at La Balsa, a gauging station situated less than $10 \mathrm{~km}$ upstream of the hydropower plant, has a marked seasonal discharge pattern. The lowest discharge occurs from July to September while the peak discharge occurs usually in March and is almost 9 times greater. Variations in discharge closely follow precipitation seasonality, typical of the outer tropics where more than $80 \%$ of precipitation falls between October and May, and the austral winter months of June to September have essentially zero precipitation. In the Rio Santa watershed glacial melt provides 10 to $20 \%$ of the total annual discharge, and may exceed $40 \%$ in the dry season (Mark et al., 2005).
The average annual average air temperature is less variable than the daily temperature range, as is typical of the tropics. Contrasting with mid-latitudes, the absence of any major thermal seasonality in the tropics causes glacier ablation throughout the year (Kaser et al., 1999). The year round ice melt that occurs in the relatively steady ablation area provides melt water some stability in its hydrochemical signature that makes tropical glacier-fed watersheds of particular interest for hydrochemical basin characterisation. In addition, by limiting the seasonality of the snow cover extent, the relative thermal steadiness marginalises its effects.

The Querococha valley (Fig. 1b) is situated between 4000 and $5150 \mathrm{ma}$ a.s.l. The Querococha Lake, with an area of $1.4 \mathrm{~km}^{2}$, marks its outlet. The two main streams within the watershed drain directly into the lake, one from the Yanamarey and G2 glaciers and the other from a non-glacierized valley. The basin contains steep sided flat-bottomed valleys filled with Quaternary sediments. As of 2005, the Yanamarey glacier has an area of $0.89 \mathrm{~km}^{2}$ and is situated between 4650 and $5150 \mathrm{~m}$ a.s.1. The G2 glacier is slightly larger with a total surface area of $1.1 \mathrm{~km}^{2}$, and is situated between 4800 and $5150 \mathrm{~m}$ a.s.l. (Racoviteanu, 2005). Combined, the glaciers cover $3 \%$ of the total catchment area. The Querococha basin is mainly composed of the sedimentary, highly weathered, Chicama formation. It includes also a limited plutonic intrusion present around the south and west boundaries (Love et al., 2004).

\section{Methodology}

For tracers that are conservative at the basin scale, it is assumed that the mass at a given point within a sub-basin is derived entirely from source components, which in the dry season tropical proglacial setting are assumed to be glacial melt water, groundwater and up-gradient nested streams. The hydrochemical basin characterisation method (HBCM) uses a multi-component mass balance approach to identify the relative or absolute contributions of these source components at a given point. HBCM geospatial coverage is based on dividing the watershed into nested interconnected sub-basins. Nested areas are used to compile component contributions for the total watershed. HBCM requires a minimum of $n-1$ tracers to determine the relative contribution of $n$ end-members at a mixing point.

Where instantaneous mixing can be assumed, a mass balance is applied to each selected conservative natural tracer $j$, assuming a well mixed system, with the following equation:

$C_{\mathrm{tot}_{j}}=\frac{\sum_{i=1}^{n}\left(C_{i_{j}} Q_{i}\right)+\varepsilon_{j}}{Q_{\mathrm{tot}}}$

$C_{\text {tot }_{j}}$ and $C_{i_{j}}$ represent the relative concentration or proportion of a tracer $j$ at mixing point and at one of the $n$ identified 


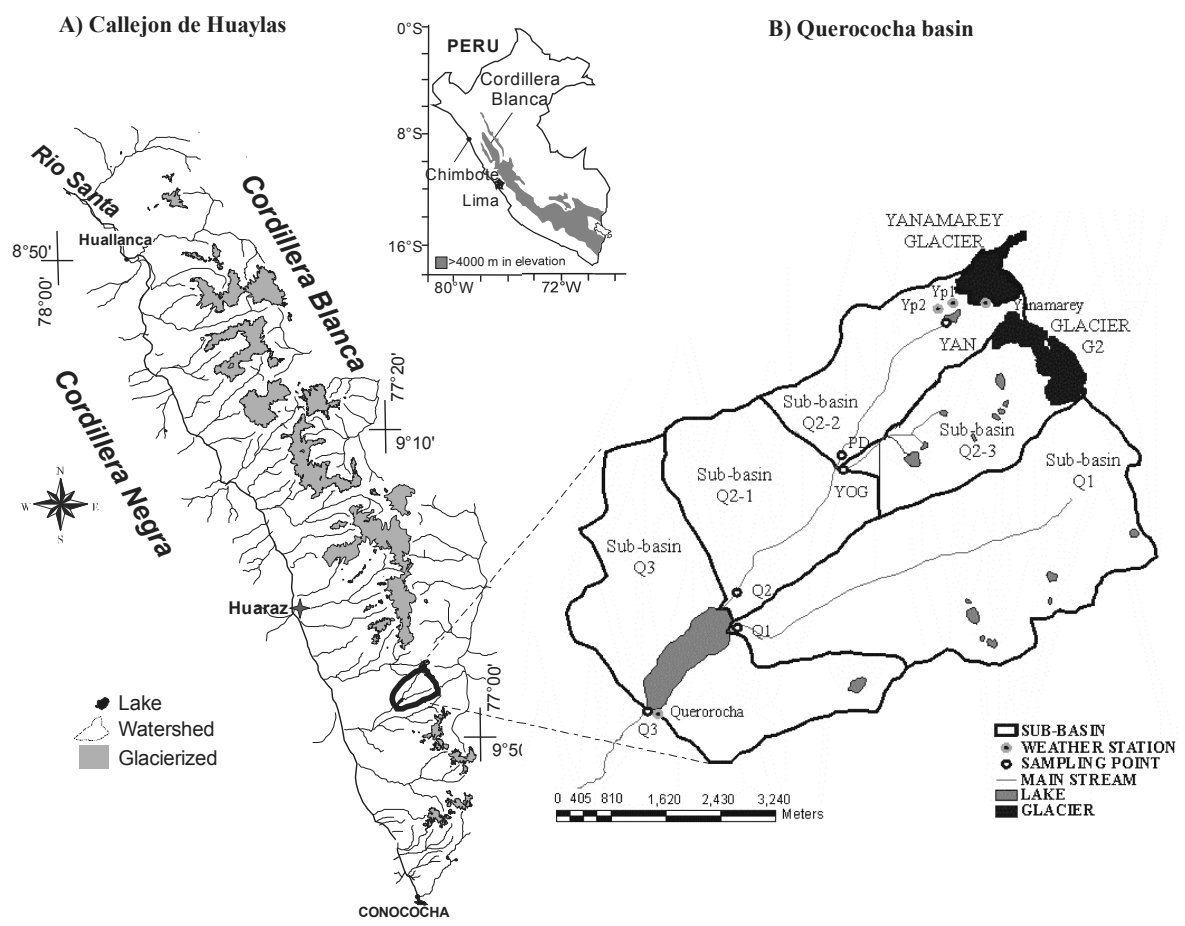

Fig. 1. Map of study area. (A) Callejon de Huaylas map; (B) Querococha Basin map. Sub-basins are delineated for using the HBCM.

potential end members $i$, respectively; $Q_{\text {tot }}$ and $Q_{i}$ correspond to the total discharge at the mixing point and the proportional contribution of the tracer $i$ and $\varepsilon_{j}$, which ideally tends to zero, corresponds to the accumulation of inaccuracies, uncertainties, errors, and approximations that can occur during the sampling, handling, and analysis for the tracer $j$.

The HBCM solves for the unknown $\frac{Q_{i}}{Q_{\text {tot }}}$ by minimizing the cumulative residual error $\sum_{j=1}^{m} \varepsilon_{j}$ while solving the water balance within a $0.5 \%$ tolerance. The water balance is:

$$
\sum_{i=1}^{n} Q_{i}=Q_{\mathrm{tot}}
$$

In cases where mixing occurs in large water bodies such as the Querococha lake, instantaneous mixing cannot be assumed and a retention factor must be included. For lakes the mass balance Eq. (1) is modified to include a time component:

$$
\int_{t=1}^{d} C_{\text {out }_{j t}} V_{\mathrm{out}_{t}} d t+\Delta S_{j}=\varepsilon_{j}+\sum_{i=1}^{n}\left(\int_{t=1}^{d} C_{i_{j t}} V_{i_{t}} d t\right)
$$

where $t$ is time expressed in days and $d$ is the number of days between two sampling events; $V_{\text {out }_{t}}$ is the daily volume of water passing through the lake outlet between the 2 sampling events; $V_{i_{t}}$ is the volume of water supplied by an end member $i$; and $C_{\text {out }_{j t}}$ and $C_{i_{j t}}$ are the daily concentration or value of the tracer $j$ at the basin outlet and of an end member $i$ respectively. $\Delta S_{j}$ is the change in mass of tracer $j$ in the lake over the considered time period:

$$
\Delta S_{j}=\left(C_{\text {out }_{j 1}}-C_{\text {out }_{j d}}\right) V_{\text {mix }}
$$

At any time, the average value of a tracer $j$ in the lake is assumed to be the same as the concentration at the outlet $C_{\text {out }_{j t}}$. $V_{\text {mix }}$ represents a conceptual homogeneous volume of lake water (less than or equal to the total volume of the lake) that would be fully mixed during the time between the two sampling events. It is assumed that the lowest $V_{\text {mix }}$ occurs during the dry season and the highest $V_{\text {mix }}$ occurs during intense precipitation periods; therefore $V_{\text {mix }}$ is a function of measured precipitation. $C_{i_{j t}}$ the concentration of the tracer $j$ for the end member $i$ at any $t$ time of the period from 1 to $d$ is considered equal to the average value of $C_{i_{j 1}}$ and $C_{i_{j d}}$. The same rule applies to $V_{i_{t}}$ and $V_{\text {out }_{t}}$. For a given time $T$, $C_{\text {out }_{j T}}$ is therefore computed as follows:

$$
\left\{\begin{array}{l}
\int_{t=1}^{T} C_{\mathrm{out}_{j t}} V_{\mathrm{out}_{t}} d t=\int_{t=1}^{T-1} C_{\mathrm{out}_{j t}} V_{\mathrm{out}_{t}} d t+V_{\mathrm{out}_{T}} C_{\mathrm{out}_{j T}} \\
C_{\mathrm{out}_{j t}}=\frac{\sum_{i=1}^{n}\left(C_{i_{j t}} V_{i_{t}}\right)+C_{\mathrm{out}_{j(t-1)}} V_{\text {mix }}-C_{\mathrm{out}_{j t}} V_{\mathrm{out}_{t}}}{V_{\text {mix }}}
\end{array}\right.
$$

The water balance, Eq. (2), is also modified to incorporate the lake module:

$$
\sum_{i=1}^{n}\left(V_{i_{t}}\right)+P_{t}=Q_{\text {out }_{t}}-E_{t}
$$


where $P_{t}$ and $E_{t}$ correspond to the daily volume of precipitation and evaporation to and from the lake respectively. Evaporation is calculated based on a different evaluation made on the nearby Titicaca Lake (Delclaux et al., 2007). The lake module of HBCM requires sampling at two different times so that volumes flowing in and leaving the lake have a significant impact on its water concentrations. In this study, a 10 and 50 day sampling interval was used to assess residence time without being affected by seasonal changes. $\delta^{18} \mathrm{O}$ and $\delta^{2} \mathrm{H}$ are not considered as acceptable tracers for the lake component due to evaporitic isotopic fractionation and spatial/temporal variability (Gonfiantini et al., 2001).

The ability of HBCM to accurately simulate watershed hydrology is validated using a inversed mass balance Eq. (1) as proposed by Christophersen et al. (1990). The principle of that validation step is that back-calculated concentrations based on a multi tracer mass balance calculation should match the measured values of any tracer taken individually.

Among the most critical conditions for HBCM application are the conservative behaviour of tracers within the study area and its ability to identify the end-members uniquely and distinctly (Soulsby et al., 2003). For the HBCM, a set of criterion are used to select applicable ions or isotopes. These are:

1. The tracer must have a consistently conservative behaviour. For the HBCM, non-conservative behaviour is defined as a tracer, as measured at a mixing point within the watershed, having a value outside the range defined by the end-members.

2. The measured tracer value at the mixing point and a minimum of one end member must be above the detection limit of the analytical methods.

3. There should be a minimum $20 \%$ difference between extremes in end-member tracer values.

Compliance of the three requirements is evaluated. Tracers that demonstrate compliance to the 3 requirements are used for HBCM application.

The Querococha watershed is divided into 5 sub-basins (Q1, Q2-1, Q2-2, Q2-3, and Q3, Fig. 1b) defined using SRTM DEM data, with areas calculated using ArcGIS. The GLIMS glaciers database (Racoviteanu, 2005) was used to define the 2005 glacial coverage. The primary geospatial characteristics of the Querococha watershed and delineated sub-basins are summarized in Table 1.

The HBCM was applied to hydrochemical data sets from the Querococha watershed using a synoptic sampling approach whereby water samples are taken from a wide variety of sources in a very short time span (Mark and Seltzer, 2003; Mark et al., 2005; Mark and McKenzie, 2007). Synoptic sampling captures the instantaneous end members and mixtures chemical and isotopic signatures of tracers that are time dependant. This is the case for examples of the stable isotopes of water. Oxygen 18 and deuterium undergo fractioning on many occasions that makes isotopic signatures difficult to be season long end member specific. The buffering effects of natural reservoirs such as aquifers and proglacial lakes allows temporal signatures to remain valid long enough to be used at all the different studied mixing points of the basin, with the exception of the Querococha lake. Spatially, it is assumed that the hydrochemical composition of endmembers is homogeneous throughout the watershed as the bedrock geology is nearly uniform in the study area. The hydrochemical composition of the lowest measured discharge from the non-glacierized sub-basin (Q1) is assumed to be representative of basin-wide groundwater. Samples taken of the Yanamarey glacier melt (Yan) are used to represent both the Yanamarey and G2 glaciers melt waters. Annual samplings are detailed at Table 2 .

For each sample collected, electrical conductivity, $\mathrm{pH}$, and temperature are measured directly in the field. Samples for laboratory analysis are filtered onsite and stored in completely filled HDPE 30 or $60 \mathrm{ml}$ bottles and stored at $4^{\circ} \mathrm{C}$ whenever possible. Major anions $\left(\mathrm{F}^{-}, \mathrm{Cl}^{-}, \mathrm{Br}^{-}, \mathrm{NO}_{2}^{-}\right.$, $\mathrm{NO}_{3}^{-}, \mathrm{SO}_{4}^{2-}$ ) were measured by ion chromatography and major cations $\left(\mathrm{Fe}^{2+}\right.$ and $\mathrm{Fe}^{3+}, \mathrm{Ca}^{2+}, \mathrm{Mg}^{+}, \mathrm{K}^{+}, \mathrm{Na}^{+}, \mathrm{Sr}^{2+}$ ) and silica $\left(\mathrm{S}_{i} \mathrm{O}_{2}\right)$ were measured using either ion chromatography, atomic absorption/emission, or direct current plasma spectroscopy. The stable isotopes of oxygen and hydrogen $\left(\delta^{18} \mathrm{O}\right.$ and $\left.\delta^{2} \mathrm{H}\right)$ were measured by mass spectrometry at Syracuse University and The Ohio State University (Finnigan MAT Delta Plus coupled to a HDO water equilibrator). Stable isotopes results are reported using the $\delta$-notation reported relative to the Vienna-Standard Mean Ocean Water (VSMOW) standard, with an accuracy of $\pm 0.1 \%$ for $\delta^{18} \mathrm{O}$ and $\pm 1 \%$ for $\delta^{2} \mathrm{H}$.

$\mathrm{Bi}$-carbonate concentration is calculated as the difference in the solution charge balance. The sum of anions and sum of cations are calculated as the sum of the respective milliequivalent values. TDS is the sum of all ions multiplied by a 0.8 correction factor.

The geospatial location of the mixing points is used to assess the groundwater contribution variations both temporally and spatially by relating the calculated dry season groundwater relative contribution to the percent glacierized area of different sub-basin using a simple dilution model:

$G l_{\%}=\frac{\frac{q_{g w}}{q_{g l}}\left(100-A_{g l}\right)}{\left(A_{g l}+\frac{q_{g w}}{q_{g l}}\left(100-A_{g l}\right)\right)}$

where $A_{g l}$ and $G l \%$ represent the percentage of glacierized surface for the sub-basin whose mixing point defines the outlet, and the rate of groundwater contribution projected at this point respectively, and $q_{g w}$ and $q_{g l}$ correspond to the groundwater and melt water specific discharge. Melt water specific discharge is defined as the volume of melt water divided by the glacier area. 
Table 1. Geospatial characteristics of the Querococha watershed and sub-basins.

\begin{tabular}{|c|c|c|c|c|c|c|}
\hline Sub-basin & Glacier & $\begin{array}{r}\% \\
\text { glacierized }\end{array}$ & $\begin{array}{r}\text { Total } \\
\text { Area }\left(\mathrm{km}^{2}\right)\end{array}$ & $\begin{array}{r}\text { Contribution } \\
\text { from } \\
\text { sub-basin }\end{array}$ & $\begin{array}{r}\text { Contribution } \\
\text { to } \\
\text { sub-basin }\end{array}$ & $\begin{array}{r}\text { Sampling } \\
\text { spots }\end{array}$ \\
\hline Q1 & - & - & 20.02 & - & Q3 & Q1 \\
\hline Q2-1 & - & - & 10.48 & Q2-2\&Q2-3 & Q3 & Q2 \\
\hline Q2-2 & Yanamarey & 9.9 & 9.02 & - & Q2-1 & PD\&Yan \\
\hline Q2-3 & G2 & 13.4 & 8.25 & - & Q2-1 & YOG \\
\hline Q2 tot & Yan\&G2 & 7.2 & 27.75 & - & Q3 & \\
\hline Q3 & - & - & 16.09 & Q1\&Q2 & Querococha & Q3 \\
\hline Querococha & Yan\&G2 & 3.1 & 63.86 & - & - & all \\
\hline
\end{tabular}

The HBCM and dilution model results are compared for dry-seasons with sufficient data using a non-linear regression analysis, specifically for 1998, 1999, 2006, and 2007. A strong correlation between the dilution model and the HBCM results suggests that the relative groundwater contribution is broadly distributed across the sub-basins whereas a weak correlation would suggest that groundwater input is spatially dependent.

The $q_{g w} / q_{g l}$ ratio, calculated by fitting the dilution model to the HBCM results, is an indicator of the relative importance of groundwater input to the basin discharge; a dryseason characterised by a high $q_{g w} / q_{g l}$ ratio indicates a high input of groundwater to total system discharge. In this study, the $q_{g w} / q_{g l}$ ratio is used as a metric of groundwater contribution to the dry season Querococha basin discharge.

Finally the ratios computed at the modeling stage are compared to normalised precipitation records from onsite rain gages to evaluate what influence the past precipitation amounts have on the relative dry season contribution of groundwater at the basin scale. The historical precipitation record spans 1981-1999 for the Yanamarey meteorological station $\left(09^{\circ} 39^{\prime} 26^{\prime \prime} \mathrm{S} ; 77^{\circ} 16^{\prime} 20^{\prime \prime} \mathrm{W}\right)$ data and 2001-2007 for the new Yanamarey station $\left(09^{\circ} 39^{\prime} 33^{\prime \prime} \mathrm{S} ; 77^{\circ} 16^{\prime} 17^{\prime \prime} \mathrm{W}\right)$. The 1982-1999 time-series is complete from September 1981 to August 1994 but is missing 54\% of monthly data from September 1994 to July 1999. The missing data are reconstructed from the Querococha meteorological station $11 \mathrm{~km}$ away $\left(09^{\circ} 43^{\prime} 43^{\prime \prime} \mathrm{S} ; 77^{\circ} 19^{\prime} 49^{\prime \prime} \mathrm{W}\right)$ using a linear transform function. The 2001-2007 time series is missing $60 \%$ of the monthly totals data. The missing data are reconstructed using the average of two nearby totalizing rain gauges, YP1 $\left(09^{\circ} 39^{\prime} 20^{\prime \prime} \mathrm{S} ; 77^{\circ} 16^{\prime} 34^{\prime \prime} \mathrm{W}\right)$ and YP2 $\left(09^{\circ} 39^{\prime} 24^{\prime \prime} \mathrm{S} ; 77^{\circ} 16^{\prime} 49^{\prime \prime} \mathrm{W}\right)$. Computed $q_{g w} / q_{g l}$ ratios from the 1998, 1999, 2006, and 2007 dry-seasons are compared to normalized monthly antecedent precipitations for periods of 1 to 60 months using a Pearson correlation test $(\alpha=0.05)$.
Table 2. Description of dry season yearly samplings performed at the Querococha basin between 1998 and 2007. Blanks indicate no data available.

\begin{tabular}{lrrrrrrr}
\hline $\begin{array}{l}\text { Mixing } \\
\text { Point }\end{array}$ & 1998 & 1999 & 2004 & 2005 & 2006 & 2007 & Total \\
\hline Q3 & 2 & 2 & 1 & 1 & 1 & 2 & 9 \\
Q1 & 2 & 2 & 1 & 1 & 1 & 2 & 9 \\
Q2 & 2 & 2 & 1 & 1 & 1 & 2 & 9 \\
YOG & & & 1 & 1 & 1 & 1 & 4 \\
PD & & & & & 1 & 3 & 4 \\
Yan & 2 & 2 & 4 & 1 & 1 & 2 & 12 \\
Total & 8 & 8 & 8 & 5 & 6 & 12 & 47 \\
\hline
\end{tabular}

\section{Results and discussion}

The nine tracers that meet the usability criterion for HBCM are conductivity, bicarbonate, magnesium, sum of anions, sulphate, TDS, hydrogen ion, and the two stable isotopes of water. Figure 2, a box plot of relative concentration for individual variables, shows that the selected variables provide end-members with a unique and distinct signature that can be used to differentiate end-member contribution in mixing equations. Results show that the high sulphate concentrations ( $>50 \mathrm{ppm}$ on average) in the glacial melt provide a signature that is exclusive to the melt water. The oxidation of the pyrite present in the Jurassic Chicama formation that underlies most of the Querococha basin is the likely origin of these anomalously high sulphate values (Mark et al., 2005). High sulphate concentrations also affect the conductivity, TDS, and sum of anions, thereby enhancing hydrochemical differences between end members. The acidic $\mathrm{pH}$ of the melt water may be due to the formation of sulphuric acid from the dissolution of this pyrite or other potential sulphides.

The back-calculation HBCM validation was conducted on sulphate, the tracer with the largest concentration range between the end members. Figure 3 compares sulphate 


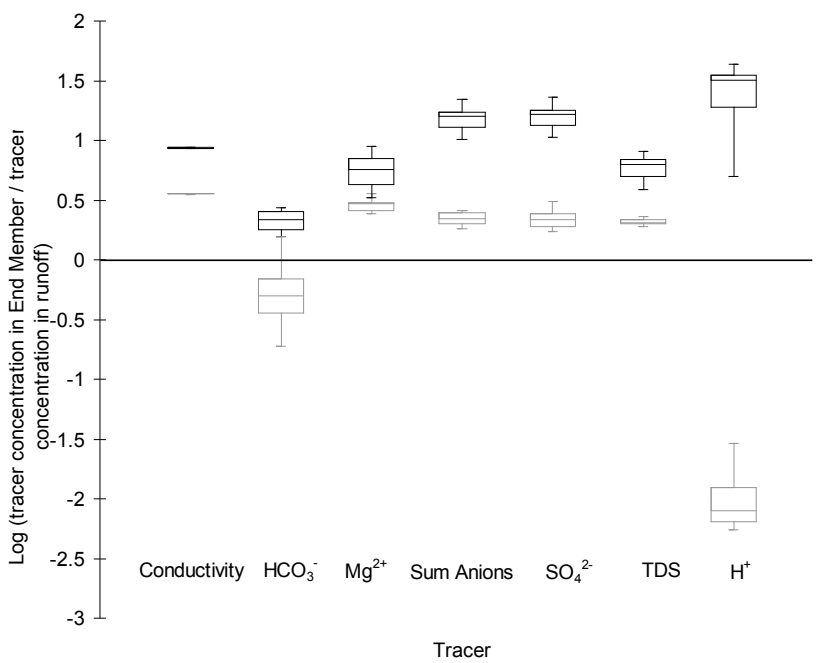

Fig. 2. End member hydrochemical signature as related to tracer selection. Boxplots represent the log of the tracer's concentration, normalized to its runoff concentration for melt water (dark line) and groundwater (grey line). Relative measures are computed by dividing individual values by the average tracer measure in runoff.

concentrations back-calculated from HBCM results with the measured concentrations at all mixing points of the Q2 subbasin. The coefficient of determination $\left(R^{2}\right)$ resulting from that comparison is 0.96 . Considering that back calculated concentrations originates from two consecutive uses of the same mass balance equation and that intermediate results were based on three to five different tracers, we can consider this determination coefficient as an indicator of very good HBCM performance.

The HBCM was used for all of the mixing points within the partially glacierized Q2 sub-basin for the dry seasons of sampled years to determine the relative contribution of melt water and groundwater to surface water (Table 3). The median relative contribution of groundwater at the Q2 mixing point is $59 \%$ of the total discharge, indicating that groundwater is the dominant end member in more than half of the studied dry seasons. This corroborates that groundwater is a major dry season contributor to streams in this glacier fed tropical basin. The largest calculated Q2 groundwater contribution was $74 \%$ in 2007 and the minimum contribution was $18 \%$ in 1998 . The resulting $56 \%$ range of relative groundwater contribution over the studied period indicates a high degree of inter-annual variability. With such high variability and dominant overall contribution, groundwater appears to be as important as melt water in contributing dry season stream flow at the Q2 point. Modeling the pro-glacial hydrology for this catchment would therefore require incorporating realistic groundwater contribution processes.

Geospatial variation in relative end member contribution is calculated for the 2006 and 2007 dry seasons, the only years with sufficient sample coverage (Fig. 4). The HBCM

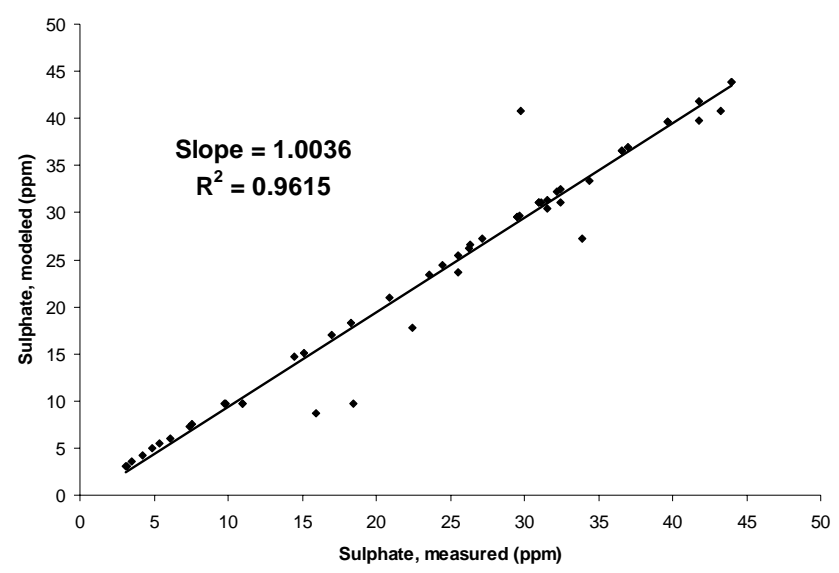

Fig. 3. Comparison between measured and calculated sulphate concentrations at all mixing points on the $\mathrm{Q} 2$ sub-basin.

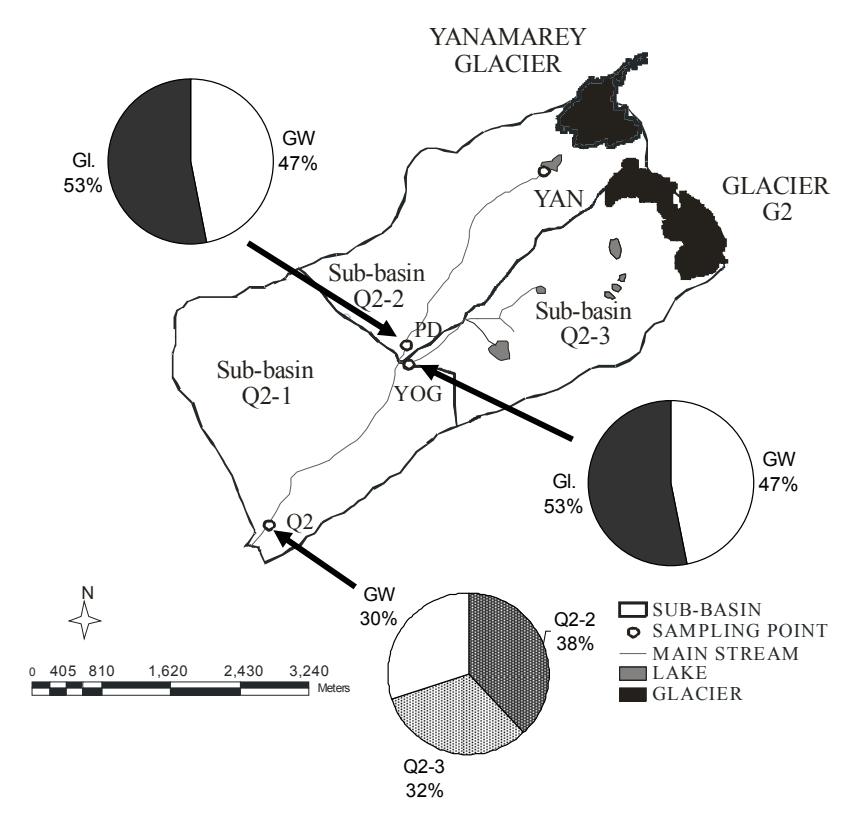

Fig. 4. 2006-2007 dry seasons end members and tributaries relative contribution to surface flows of the Q2 basin. Each pie-chart related to the sub-basin map represents the average contributions at the pointed mixing point. Groundwater is represented in white and melt water in black. For the 2006-2007 dry season the overall Q2 relative contribution is 30\% from glacial melt and 70\% from groundwater.

results show that the two glacierized sub-basins, Q2-2 and Q2-3, both have similar relative groundwater contributions during the dry season. This is potentially related to the similar geomorphologic characteristics these two sub-basins exhibit. They both have comparable basin size, glacier orientation and elevation range and show a slight difference only in the percentage of glacierized area (Table 1). The results also show that, at the Q2-1 non glacierized catchment, 
Table 3. Prediction of relative groundwater contribution (\%) during the dry season at the Querococha watershed outlet, Q2, and PD mixing points. Empty cells indicate insufficient data.

\begin{tabular}{lrrrrrrrrr}
\hline & $A_{g l}(\%)$ & 1998 & 1999 & 2004 & 2005 & 2006 & 2007 & Average & Median \\
\hline Outlet & 3.1 & 42 & 68 & & & & 79 & & \\
Q2 & 7.2 & 18 & 52 & 71 & 46 & 65 & 74 & $\mathbf{5 4}$ & $\mathbf{5 9}$ \\
PD & 9.9 & & & & & 49 & 46 & & \\
\hline
\end{tabular}

groundwater contributes to almost half of the total outflow of Q2-2 and Q2-3. As three sub-basins present an important groundwater contribution, it can be concluded that groundwater input does not only occur in particular sub-catchment of the Q2 basins, but is distributed throughout them all.

How similar the sub-basins are in generating groundwater is studied by using the mixing model (Eq. 8).The nonlinear regression analysis between percentage of glacierized area of a sub-basin and its relative groundwater contribution provides first an indication of how well the model fits with the HBCM findings. Results from the analysis for the years 1998, 1999, 2006 and 2007 made using Q2, Q3 and Yan Pampa down as distributed watersheds are presented in Table 4. The model fit is evaluated through the coefficient of determination $\left(R^{2}\right)$ that ranges from 0.97 to 1.00 indicating a close relationship between the HBCM calculated groundwater contributions and the dilution model and that there is no dominant relationship between sub-catchment geographic position and the pattern of groundwater contribution to stream flow. What happens within the sub-basin is not discerned by HBCM. Localised disparities in groundwater contribution like surface water contribution to groundwater spots (i.e. a losing stream reach) may exist but would require a finer HBCM spatial resolution to be identified.

The regression analysis also provides yearly computed values of the model parameter $q_{g w} / q_{g l}$. Over the four studied years, this ratio varies from 0.02 to 0.13 . These values translate specific contributions of melt water $q_{g l}$, defined as melt water discharge divided by glaciated area, that are 8 to 50 times greater than that of groundwater. Normalized $q_{g w} / q_{g l}$ ratios show that relative groundwater contributions are lower in 1998 and 1999 than in 2006 and 2007. By definition, this lower relative contribution of groundwater in 19981999 maybe due to a $q_{g w}$ being lower than in 2006-2007, a higher $q_{g l}$ or a combination of both. The Yanamarey glacier mass balance presented in Bury et al. (2009) for the 19992008 period shows that the glacier absolute contribution was higher in 2006-2007 than in 1999, suggesting that the low 1998-1999 relative groundwater contribution was a consequence of a low $q_{g w}$. Antecedent precipitation normalized to the 1982-2007 monthly average, presented in Table 5, suggests that low groundwater yields may be related to the lack of precipitation that occurred months and/or years ahead of July 1998. This relation is confirmed by results of the cor-
Table 4. Dilution model (Eq. 8) results for groundwater contributions to Querococha discharge for the 1998, 1999, 2006 and 2007 dry seasons. $q_{g w} / q_{g l}$ represents the ratio of groundwater and meltwater specific discharges. Normalized $q_{g w} / q_{g l}$ is the $q_{g w} / q_{g l}$ ratio minus the average $q_{g w} / q_{g l}$ value from 1998, 1999, 2006 and 2007 dry seasons. $R_{\text {model }}^{2}$ is the coefficient of determination that describes how the HBCM calculated relative contribution of endmembers fits with the dilution model.

\begin{tabular}{lrrrrr}
\hline Modelisation & 1998 & 1999 & 2006 & 2007 & Average \\
\hline$q_{g w} / q_{g l}$ & 0.02 & 0.08 & 0.12 & 0.13 & 0.1 \\
Normalised $q_{g w} / q_{g l}$ & -0.08 & -0.03 & 0.02 & 0.03 & \\
$R_{\text {model }}^{2}$ & 0.99 & 1.00 & 0.99 & 0.97 & \\
\hline
\end{tabular}

relation study conducted on the normalized $q_{g w} / q_{g l}$ ratios and the antecedent precipitation. These results are expressed both as statistically representative correlation coefficient, $r_{x y}$, and the P-value (Table 5). Of the 10 considered normalized precipitation periods, four present a significant $(\alpha=0.05)$ correlation with the normalized $q_{g w} / q_{g l}$ ratio. These periods are the antecedent 3, 18, 24 and 36 months. This result suggests that the dry season relative groundwater contribution is influenced both by a short and recent period ( 3 months before dry season) as well as by a long and older period (from 18 to 36 months prior studied dry season) of antecedent precipitation. The different contributing periods suggests the existence of both short and longer groundwater pathways from surface infiltration to stream discharge. At antecedent periods greater than 48 months there is very little precipitation influence, indicating that the groundwater contribution to the surface water system has a maximum age of four years.

\section{Conclusions}

By combining limited physical hydrology data with hydrochemical data through the HBCM analysis, it is possible to estimate source contributions to a glaciated watershed in the tropics and to make initial connections between climate and hydrology. While the HBCM was only used for the Querococha basin and sub-basins within, it is easily adaptable to other tropical or subtropical proglacial valleys where the 
Table 5. Precipitation/groundwater relative contribution correlation results to Querococha discharge for the 1998, 1999, 2006, and 2007 dry seasons. Normalized precipitation, $P_{m}$, is the antecedent precipitation, normalized to the 1982-2007 monthly average, for $m$ months prior to the month of July. Normalized precipitation is expressed in mm. $r_{x y}$ is the correlation coefficient for the $q_{g w} / q_{g l}$ ratios and the normalized precipitation. Only the statistically representative $r_{x y}$ are presented.

\begin{tabular}{lrrrrrr}
\hline$P_{m}$ & 1998 & 1999 & 2006 & 2007 & P-value & $r_{x y}{ }^{*}$ \\
\hline$P_{1}$ & -12 & 39 & 52 & -12 & 0.667 & \\
$P_{2}$ & -53 & 85 & 11 & 16 & 0.573 & \\
$P_{3}$ & -130 & 9 & 114 & 162 & $\mathbf{0 . 0 0 4}$ & $\mathbf{0 . 9 9 6}$ \\
$P_{6}$ & -380 & 408 & 213 & 23 & 0.427 & \\
$P_{12}$ & -560 & 89 & 129 & 165 & 0.083 & \\
$P_{18}$ & -576 & -291 & 63 & 378 & $\mathbf{0 . 0 4 4}$ & $\mathbf{0 . 9 5 6}$ \\
$P_{24}$ & -679 & -470 & 197 & 294 & $\mathbf{0 . 0 4 1}$ & $\mathbf{0 . 9 5 9}$ \\
$P_{36}$ & -992 & -589 & 403 & 362 & $\mathbf{0 . 0 3 0}$ & $\mathbf{0 . 9 7 0}$ \\
$P_{48}$ & -1307 & -903 & 780 & 568 & 0.058 & \\
$P_{60}$ & -815 & -1218 & 896 & 946 & 0.182 & \\
\hline
\end{tabular}

* significant for alpha $=0.05$.

impact of glacial retreat on water resource needs to be assessed. It provides a method of delineating source contributions without a major investment in infrastructure for hydrologic measurements. Querococha, our pilot watershed, is now better instrumented and has more historical data than most glaciated watershed in the tropics. Actual instrumentation, that includes both upstream and downstream gauging stations, is planned to further refine HBCM results, for example by increasing the temporal resolution and to identify end members at the year scale.

The HBCM results show considerable temporal variability in volumetric groundwater contributions. Of the studied dry seasons, groundwater is a dominant contributor to the Querococha surface water. The analysis of antecedent precipitation patterns before each dry season indicates that groundwater follows both a fast (three months) and a slow (three years) flow systems. This may reflect local and intermediate flow systems or other hydrogeological complexities that are not the focus of the HBCM. Further research is required to assess the groundwater processes that control this system.

The present study demonstrates that modeling pro-glacial catchments such as Querococha or other comparable basins requires incorporating adequate groundwater contributions and mechanisms. With a relative contribution that varies from 18 to $74 \%$ for a basin that, like the entire Cordillera Blanca, is $7 \%$ glaciated, pro-glacial groundwater contributions are a key component of the dry season local hydrogeological system and possibly of the entire Cordillera Blanca. Neglecting this groundwater component in proglacial hydrology modeling would therefore lead to incomplete and inaccurate projections at annual and climatically appropriate time scales.
Both of the glaciers in the Querococha basin are rapidly retreating and will disappear in the coming decades. Assuming a complete loss of Querococha glaciers while maintaining current precipitation regime (Painter, 2007), the dry season discharge would be decreased by almost half of what was observed in 1998, 1999, and 2004-2007. This decrease in melt water contribution could lead to increased discharge inter-annual variability. A multi-year drought, in addition to the absence of glacial melt inputs, would cause, with possibly a one and half year delay, an even more significant drop in watershed discharge.

Acknowledgements. The authors would like to thank Marcos Zapata and Jesus Gomez, ANA, Peru for providing data and logistical support, the Ice Core Group and Ping-Nan Lin and the Byrd Polar Research Center, The Ohio State University, for stable isotope analysis. Financial support from McGill University, Geochemistry and Geodynamics Research Center (GEOTOP) of Quebec, Natural Science and Engineering Research Council (NSERC) of Canada, and The Ohio State University.

Edited by: P. Fabian

Reviewed by: two anonymous referees

\section{References}

Anderson, S. P.: Glaciers show direct linkage between erosion rate and chemical weathering fluxes, Geomorphology, 67(1-2), 147157, 2005.

Barnett, T. P., Adam, J. C., and Lettenmaier, D. P.: Potential impacts of a warming climate on water availability in snow-dominated regions, Nature, 438, 7066, 303-309, 2005.

Barry, R. G.: The status of research on glaciers and global glacier recession: a review, Prog. Phys. Geog., 30(3), 285-306, 2006.

Brown, L. E., Hannah, D. M., Milner, A. M., Soulsby, C., Hodson, A. J., and Brewer, M. J.: Water source dynamics in a glacierized alpine river basin (Taillon-Gabietous, French Pyrenees), Water Resour. Res., 42(8), W08404, doi:10.1029/2005WR004268, 2006.

Bury, J., Mark, B. G., McKenzie, J. M., French, A., Baraer, M., and In Huh, K.: Glacier recession and human vulnerability in the Yanamarey watershed of the cordillera Blanca, Peru, Climatic Change, in review, 2009.

Christophersen, N., Neal, C., Hooper, R. P., Vogt, R. D., and Andersen, S.: Modeling streamwater chemistry as a mixture of soiwater end-members. A step towards 2 nd generation acidification models, J. Hydrol., 116(1-4), 307-320, 1990.

Delclaux, F., Coudrain, A., and Condom, T. : Evaporation estimation on Lake Titicaca: a synthesis review and modelling, Hydrol. Process., 21(13), 1664-1677, 2007.

Favier, V., Coudrain, A., Cadier, E., Francou, B., Ayabaca, E., Maisincho, L., Praderio, E., Villacis, M., and Wagnon, P.: Evidence of groundwater flow on Antizana ice-covered volcano, Ecuador, Hydrolog. Sci. J., 53(1), 278-291, 2008.

Gonfiantini, R., Roche, M. A., Olivry, J. C., Fontes, J. C., and Zuppi, G. M.: The altitude effect on the isotopic composition of tropical rains, Chem. Geol., 181(1-4), 147-167, 2001. 
Hood, J. L., Roy, J. W., and Hayashi, M.: Importance of groundwater in the water balance of an alpine headwater lake, Geophys. Res. Lett., 33(13), L13405, doi:10.1029/2006GL026611, 2006.

IPCC: Climate Change 2007: Impacts, Adaptation and Vulnerability, IPCC (Intergovernmental Panel on Climate Change), Cambridge, 976 pp., 2007.

Kaser, G. and George, C.: On the mass balance of low latitude glaciers with particular consideration for glacier-climate studies on a tropical high mountain site, Geogr. Ann. A, 81A(4), 643$651,1999$.

Kaser, G., Cogley, J. G., Dyurgerov, M. B., Meier, M. F., and Ohmura, A.: Mass balance of glaciers and ice caps: Consensus estimates for 1961-2004, Geophys. Res. Lett., 33(19), L19501, doi:10.1029/2006GL027511, 2006.

Love, D. A., Clark, A. H., and Glover, J. K.: The lithologic, stratigraphic, and structural setting of the giant antamina copper-zinc skarn deposit, Ancash, Peru, Econ. Geol. Bull. Soc., 99(5), 887916, 2004

Mark, B. G. and Seltzer, G. O.: Tropical glacier meltwater contribution to stream discharge: a case study in the Cordillera Blanca, Peru, J. Glaciol., 49(165), 271-281, 2003.

Mark, B. G., McKenzie, J. M., and Gomez, J.: Hydrochemical evaluation of changing glacier meltwater contribution to stream discharge: Callejon de Huaylas, Peru, Hydrolog. Sci. J., 50(6), 975987, 2005.

Mark, B. G. and McKenzie, J. M.: Tracing increasing tropical Andean glacier melt with stable isotopes in water, Environ. Sci. Technol., 41(20), 6955-6960, 2007.

Nogues-Bravo, D., Araujo, M. B., Errea, M. P., and Martinez-Rica, J. P.: Exposure of global mountain systems to climate warming during the 21st Century, Global Environ. Chang., 17(3-4), 420 428, 2007.
Painter, J.: Deglaciation in the Andean Region, Human Development Report 2007/2008, UNDP, Human Development Report Office, 21 pp., 2007.

Pouyaud, B.: Impact of climate change on water resources: the Rio Santa Basin (White Cordillera - Peru), paper presented at CONAM meeting, Bonn, Germany, 2004.

Pouyaud, B., Zapata, M., Yerreb, J., Gomez, J., Rosas, G., Suarez, W., and Ribstein, P.: On the future of the water resources from glacier melting in the Cordillera Blanca, Peru, Hydrolog. Sci. J., 50(6), 999-1022, 2005.

Racoviteanu: GLIMS Glacier Database, edited, National Snow and Ice Data Center/World Data Center for Glaciology, 2005.

Soulsby, C., Brewer, M. J., Dunn, S. M., Ott, B., and Malcolm, I. A.: Identifying and assessing uncertainty in hydrological pathways: a novel approach to end member mixing in a Scottish agricultural catchment, J. Hydrol., 274(1-4), 109-128, 2003.

Suarez, W., Chevalier, P., Pouyaud, B., and Lopez, P.: Modelling the water balance in the glacierized Paron Lake basin (White Cordillera, Peru), Hydrolog. Sci. J., 53(1), 266-277, 2008.

Vuille, M., Francou, B., Wagnon, P., Juen, I., Kaser, G., Mark, B. G., and Bradley, R. S.: Climate change and tropical Andean glaciers: Past, present and future, Earth-Sci. Rev., 89(3-4), 7996, 2008

Wagnon, P., Ribstein, P., and Schuler, T.: Flow separation on Zongo Glacier, Cordillera Real, Bolivia, Hydrol. Process., 12(12), 1911-1926, 1998. 